\title{
APPLICATION OF CHOSEN METHODS OF ROBUST ESTIMATION: BAARDA'S AND HUBER'S IN SEARCH FOR OUTLIERS IN THE REAL ESTATE MARKET MODELING*
}

Beata Śpiewak, M.Sc.

AGH University of Science and Technology

Faculty of Mining Surveying and Environmental Engineering

Departament of Geomatics

A. Mickiewicza 30, 30-059 Kraków, Poland

e-mail:spiewak@agh.edu.pl

Received 30 October 2017, Accepted 25 March 2018

\begin{abstract}
In the article, an attempt was made to compile a dataset which was devoid of outliers, on the example of Cracovian apartment market. Robust estimation was the tool which was used, but only its two methods were considered: Baarda's and Huber's. Huber's method belongs to the so-called active methods which means that it allows to eliminate gross errors during the estimation of the parameters of multiple linear regression where a unit price is called a dependent variable or forecasted one. Baarda's method is a passive method which is based on statistical tests and allows, after determining the parameters of a multiple linear regression model, to indicate the observations which may be burdened with gross errors. Thus both mentioned algorithms differ from each other substantially. In this publication, Baarda's and Huber's methods were compared in the context of their effectiveness for the analyzed dataset, and as tools of preparing the data for further analysis. The results showed that Baarda's method is more appropriate for the analyzed dataset than Huber's algorithm, but it does not mean that the active method is worse.
\end{abstract}

Keywords: market analysis, Baarda's method, Huber's method, robust estimation, multiple linear regression

JEL classification: C13, R30, R39

\footnotetext{
${ }^{*}$ This article was funded by a dean's grant no. 15.11.150.456 in the Department of Geomatics, AGH University of Science and Technology, Kraków, Poland.
} 


\section{Introduction}

Real estate market modeling is preceded by collecting data about the properties which were sold on the analyzed market at a set time. It is important to notice that the information gained from the real estate market without a search key is claimed to be random. It means that, among them, the observations can appear which are atypical to the others called outliers (Ramsey, 1969; Walesiak, 1996; Smith, Everett, 2002; Doszyń, Gnat, 2017). To conduct correct conclusions about the relations on the analyzed market, the influence of such observations should be minimized or completely eliminated. Algorithms of robust estimation are statistical methods which give the possibility to restrain the influence of outliers on the statistical model which describes dependences on the examined market (Huber, 1981; Prószyński, Kwaśniak, 2002). Unfortunately, two problems can appear. One concerns the threat that outliers send a very important message from the market that there are some significant changes in the area. The second one is about adjusting the data to the model instead of adjusting the model to the data. In this article, the author compares two methods of searching outliers and tries to solve the above problems.

This publication is the continuation of the author's research on the application of robust estimation in the real estate market modeling (Śpiewak, 2018).

\section{Chosen algorithms of robust estimation}

In the scientific literature, two groups of robust estimation are discussed: passive and active methods (Kamiński, 2003). Statistical tests are the basis of the passive methods, which allow, after determining the parameters of a statistical model by using the least squares method, to indicate these observations which may be burdened with gross errors (Ligas, 2010). The active methods, contrary to the passive methods, allow to minimize the influence of outliers during the estimation of model parameters by introducing weights. The model which will be used in the calculations is multiple linear regression (Isakson, 1998; Bitner, 2007; Barańska, 2010).

The estimation of the parameters of multiple linear regression is conducted on the basis of data about the properties which were sold on the analyzed market at a set time. Furthermore, it is claimed that a unit price is the forecasted variable, dependent on the property features which are called explanatory variables. The model can be presented by using a matrix notation in the following formula (Barańska, 2007):

$$
[C]=[X] \times[a]+[\delta]
$$


where:

$$
\begin{aligned}
& {[C]=\left[\begin{array}{c}
c_{1} \\
c_{2} \\
\vdots \\
c_{n}
\end{array}\right] \quad-\text { a vector of the forecasted variable (a unit price), }} \\
& {[X]=\left[\begin{array}{cccc}
1 & x_{11} & \cdots & x_{1 m} \\
1 & x_{21} & \cdots & x_{2 m} \\
\vdots & \vdots & \ddots & \vdots \\
1 & x_{n 1} & \cdots & x_{n m}
\end{array}\right]-\begin{array}{l}
\text { a matrix which contains the values of the explanatory variables } \\
\text { (property features) }
\end{array}} \\
& {[a]=\left[\begin{array}{c}
a_{0} \\
a_{1} \\
\vdots \\
a_{m}
\end{array}\right] \quad-\text { a vector of the multiple linear regression coefficients, }} \\
& {[\delta]=\left[\begin{array}{c}
\delta_{1} \\
\delta_{2} \\
\vdots \\
\delta_{n}
\end{array}\right] \quad-\text { a vector of model random deviations (differences between the }}
\end{aligned}
$$

As a result of equation (1), solved by using the least squares method, there are:

- an unencumbered estimator of an unknown vector:

$$
\hat{a}=\left(X^{T} X\right)^{-1} \times X^{T} C
$$

- an unencumbered estimator of residual variance which describes the inaccuracy of model parameters estimation:

$$
\hat{\sigma}_{0}^{2}=\frac{C^{T} C-\hat{a}^{T} X^{T} C}{n-(m+1)}
$$

- a covariance matrix of an unknown vector (vector of model parameters):

$$
\operatorname{Cov}(\hat{a})=\hat{\sigma}_{0}^{2} \times\left(X^{T} X\right)^{-1}
$$

- a covariance matrix of model values:

$$
\operatorname{Cov}(W)=\hat{\sigma}_{0}^{2} \times X\left(X^{T} X\right)^{-1} X^{T}
$$




\subsection{Baarda's method}

In this method, it is assumed that observation corrections $v(v=-\delta)$ are random variables which have normal distribution and the value of standard deviation $\sigma_{0}$ (estimator of $\sigma_{0}$ is determined by formula 3 ) is known apriori (Baarda, 1968). After solving equation (1), according to formulas (2)-(5), the global test of the model is done by realization (6) (Prószyński, Kwaśniak, 2002):

$$
\chi^{2}=\frac{V^{T} V}{\sigma_{0}^{2}}=\frac{f \times \hat{\sigma}_{0}^{2}}{\sigma_{0}^{2}} \sim \chi^{2}(f)
$$

where:

$V$ - observation corrections (a difference between model value $W$ and its observed price $C$ ), and

$f=n-(m+1)-$ the number of freedom degrees in chi-square $\chi^{2}$ distribution $(n-$ the number of properties, $m$ - the number of attributes describing a property).

Zero hypothesis assumes that there are no gross errors in the observations. If for set relevance level $\alpha$, test statistics $\chi^{2}$ exceeds a critical value, according to the following formula:

$$
\chi^{2}>\chi_{\alpha}^{2}(f)
$$

there are no reasons to accept the zero hypothesis, and it is rejected.

An alternative hypothesis claims that there is at least one gross error in the observation set. The search for outliers is done by the test of a particular observation, according to the equation:

where:

$$
u_{i}=\frac{v_{i}}{\sigma_{v_{i}}}
$$

$v_{i}-$ an adjustment correction for $i$ observation, and

$\sigma_{v i}-$ an average correction mistake, calculated as:

$$
\begin{gathered}
\sigma_{v_{i}}=\sigma_{0} \sqrt{\left\{Q_{v}\right\}_{i i}} \\
Q_{v}=I-X\left(X^{T} X\right)^{-1} X^{T}
\end{gathered}
$$

where:

I - a unit matrix,

$Q_{v} \quad$ - a co-factor matrix of a correction vector, and

$\left\{Q_{v}\right\}_{i i}$ - a diagonal element of a co-factor matrix of a correction vector conforming $i$ observation. 
The form of the zero hypothesis $H_{0}$ - for the test of a standardised observation correction is:

$$
H_{0}: \mathrm{E}\left(v_{\mathrm{i}}\right)=0
$$

If:

$$
\left|u_{i}\right| \leq u_{\alpha / 2}
$$

where:

$u_{\alpha / 2}-$ a critical value of the test appointed from the distribution $\mathrm{N}(0 ; 1)$ for the relevance level $\alpha$ which is egual to quantile $u(1-\alpha / 2)$,

there are no reasons to reject $H_{0}$.

In the case of not realizing condition (12), the zero hypothesis $H_{0}$ is rejected, and it is assumed that the observation is supposed to contain a gross error.

If several observations do not realize (12), the observations must be deleted, and then the global test is repeated (6). Eliminating outliers is done until $\chi^{2} \leq \chi_{\alpha}^{2}(f)$.

\subsection{Huber's method}

To use Huber's method, a diagonal matrix called $P$ should be introduced to equations (2)-(5) and (10). Matrix $P$ consists of the observation weights situated on the main diagonal and the zeros above and below the main diagonal (Muszyński, Rybak, 2008). Formulas (2)-(5) and (10), after the application of $P$ matrix, have the following form:

$$
\begin{gathered}
\hat{a}=\left(X^{T} P X\right)^{-1} \times X^{T} P C \\
\hat{\sigma}_{0}^{2}=\frac{C^{T} P C-\hat{a}^{T} X^{T} P C}{n-(m+1)} \\
\operatorname{Cov}(\hat{a})=\hat{\sigma}_{0}^{2} \times\left(X^{T} P X\right)^{-1} \\
\operatorname{Cov}(W)=\hat{\sigma}_{0}^{2} \times X\left(X^{T} P X\right)^{-1} X^{T} \\
Q_{v}=P^{-1}-X\left(X^{T} P X\right)^{-1} X^{T}
\end{gathered}
$$

In the first iteration, it is assumed that all the observations have the same weight. Then, after the estimation of the vector of the multiple linear regression coefficients, the following equation is checked:

$$
|\bar{v}|=\left|\frac{v}{\sigma_{v}}\right|
$$


If its value is more than parameter $k$, then the modification of the observation weights in the next iterations is realized by the expression (Adamczyk, 2017):

where:

$$
\bar{p}(\bar{v})=\left\{\begin{array}{l}
1 \text { dla }|\bar{v}| \leq k \\
\frac{k}{|\bar{v}|} \text { dla }|\bar{v}|>k
\end{array}\right.
$$

$\bar{p}(\bar{v})-$ modified weight for every observation in the dataset.

The process of repeat calculations can be finished at the moment of obtaining high dataset coherence, set on the basis of the model variability coefficient.

\section{The application of Baarda's and Huber's method in search for outliers}

The process of searching for outliers was conducted on the basis of the multiple linear regression model, built of the information about 204 apartment sale transactions as a matter of the property law, situated in Cracovian district called Krowodrza. The transactions took place from August to December 2015 (the excerpt of the database is given in Table 1). Every property has been described by quantitative features (a transaction date, floor surface, number of rooms,

Table 1. Database of the transaction properties (extract)

\begin{tabular}{|c|c|c|c|c|c|c|c|c|c|c|c|c|}
\hline 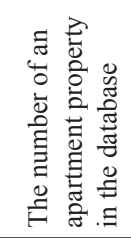 & 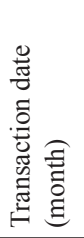 & 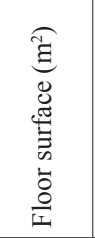 & 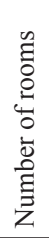 & 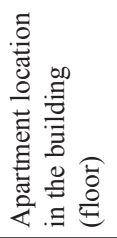 & 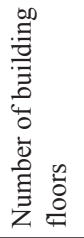 & 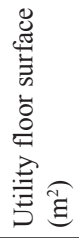 & 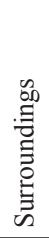 & 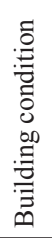 & 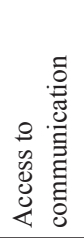 & $\begin{array}{l}0 \\
0 \\
0 \\
0 \\
0 \\
0 \\
0 \\
0 \\
0 \\
0 \\
0 \\
\dot{4} \\
\end{array}$ & 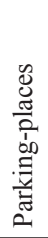 & 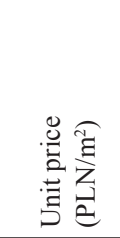 \\
\hline 1 & 1 & 49.29 & 3 & 5 & 4 & 3.00 & 5 & 5 & 4 & 5 & 2 & $6,492.19$ \\
\hline 2 & 1 & 38.00 & 3 & 5 & 3 & 4.01 & 3 & 5 & 3 & 3 & 4 & $5,789.47$ \\
\hline 3 & 1 & 30.00 & 2 & 8 & 11 & 0.00 & 4 & 3 & 4 & 4 & 4 & $6,833.33$ \\
\hline 4 & 1 & 26.03 & 1 & 2 & 4 & 0.00 & 4 & 4 & 4 & 4 & 4 & $6,146.75$ \\
\hline$\vdots$ & $\vdots$ & $\vdots$ & $\vdots$ & $\vdots$ & $\vdots$ & $\vdots$ & $\vdots$ & $\vdots$ & $\vdots$ & $\vdots$ & $\vdots$ & $\vdots$ \\
\hline 202 & 5 & 32.32 & 2 & 3 & 3 & 0.00 & 3 & 4 & 3 & 3 & 3 & $4,795.79$ \\
\hline 203 & 5 & 37.10 & 3 & 4 & 5 & 0.00 & 5 & 4 & 3 & 3 & 2 & $5,256.06$ \\
\hline 204 & 5 & 37.28 & 3 & 5 & 4 & 0.00 & 5 & 3 & 3 & 5 & 2 & $6,410.94$ \\
\hline Max. & 5 & 105.00 & 5 & 14 & 16 & 15.20 & 5 & 5 & 5 & 5 & 5 & $11,228.81$ \\
\hline Min. & 1 & 14.77 & 1 & 1 & 2 & 0.00 & 1 & 2 & 1 & 1 & 1 & $3,373.69$ \\
\hline Mean & 3 & 46.03 & 3 & 4 & 6 & 1.70 & 4 & 4 & 4 & 4 & 3 & $6,403.52$ \\
\hline $\begin{array}{l}\text { Stand. } \\
\text { deviation }\end{array}$ & 1 & 16.51 & 1 & 3 & 3 & 3.01 & 1 & 1 & 1 & 1 & 1 & $1,364.83$ \\
\hline
\end{tabular}

Source: Śpiewak (2018). 
flat location in a building (floor), number of building floors, utility floor surface, and a unit price), which did not demand graduation, and qualitative features (surroundings, a building's condition, access to communication, access to public places, and parking-places), for which the graduation from 1 to 5 was taken, where 1 meant the lowest quality and 5 meant the highest one. The transaction date was the number of the months from the date of the first transaction in the analyzed database.

\subsection{Baarda's method}

Before the calculations, the value of the standard deviation was set as $785.51 \mathrm{PLN} / \mathrm{m}^{2}$. This value is $10 \%$ of difference between the maximal price $\left(11,228.81 \mathrm{PLN} / \mathrm{m}^{2}\right)$ and the minimal price $\left(3,373.69 \mathrm{PLN} / \mathrm{m}^{2}\right)$ in the collected database. This criterion was used because the value of $10 \%$ is the maximal probability of making a so-called error of the first kind in statistical tests.

The search for outliers was initiated with the determination of equation coefficients (1) by using the least squares method (2)-(3). The next step was the verification of their influence on the unit price at the relevance level of 0.05 . Then, the estimator of residual variance (3) and test statistics $\chi^{2}(6)$ in the global test were calculated. The value of $\chi^{2}$ at the relevance level $\alpha$ $=0.05$, indicated the necessity of rejecting zero hypothesis $H_{0}$, which meant that there were outstanding transactions in the analyzed dataset. Consecutively, the test for every correction, at the relevance level $\alpha=0.05$, was conducted, according to (8)-(12). Two iterations were done and each of them was preceded by the global test (6). To sum up, 42 observations seemed to be different from their model values in the analyzed database of the properties situated in Krowodrza district.

Table 2. The results of Baarda's method for the analyzed real estate market

\begin{tabular}{|c|c|c|c|c|c|c|c|c|}
\hline $\begin{array}{l}\text { No. } \\
\text { of } \\
\text { obser. }\end{array}$ & $\begin{array}{c}\hat{\sigma}_{0} \\
(\mathrm{PLN} / \\
\left.\mathrm{m}^{2}\right)\end{array}$ & $\chi^{2}$ & $\chi^{2}(f)$ & Conclusion & $\begin{array}{c}\text { No. } \\
\text { of } \\
\text { outliers }\end{array}$ & $\begin{array}{c}\mathrm{C}_{\text {mean }} \\
\left(\mathrm{PLN} / \mathrm{m}^{2}\right)\end{array}$ & $\begin{array}{l}\text { Variability } \\
\text { coefficient } \\
V=\frac{\hat{\sigma}_{0}}{C_{\text {mean }}}\end{array}$ & $\begin{array}{c}\text { Relevant model } \\
\text { variables }\end{array}$ \\
\hline 204 & $1,241.61$ & 479.183 & $\begin{array}{c}\chi^{2}(199)= \\
232.912\end{array}$ & $\begin{array}{c}\chi^{2}>\chi^{2}(f) \\
\text { there is at least } \\
\text { one outlier in the } \\
\text { database }\end{array}$ & 42 & $6,403.52$ & 0.19 & $\begin{array}{l}\text { trans. date, } \\
\text { no. of rooms, } \\
\text { utility floor } \\
\text { surf., access to } \\
\text { public places }\end{array}$ \\
\hline 162 & 730.22 & 136.538 & $\begin{array}{c}\chi^{2}(158)= \\
188.332\end{array}$ & $\begin{array}{l}\qquad \chi^{2}<\chi^{2}(f) \\
\text { there is no outlier } \\
\text { in the database }\end{array}$ & 0 & $6,222.15$ & 0.12 & $\begin{array}{l}\text { trans. date, } \\
\text { utility floor } \\
\text { surf., access to } \\
\text { public places }\end{array}$ \\
\hline
\end{tabular}

Source: Śpiewak (2018). 
The results of the research in each iteration with relevant model variables are presented in Table 2.

Importantly, the variability coefficient changed its value from 0.19 to 0.12 after eliminating 42 observations called outliers. It meant the growth of the multiple linear regression model adjustment to the market data. The fall of $V$ value was more significant because the average unit price $C_{\text {mean }}$ also decreased, which caused the increase of the data coherence. Figures 1 and 2

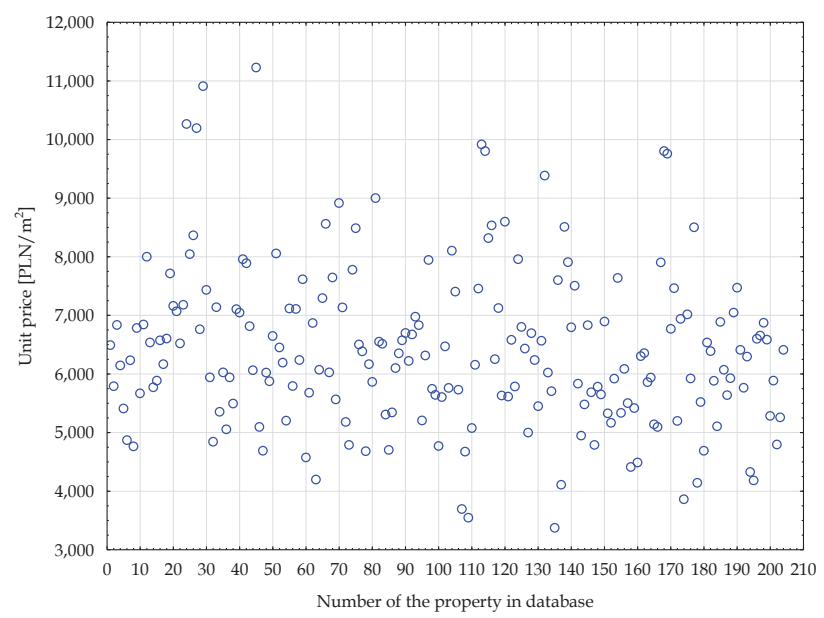

Figure 1. Dispersion graph of the unit prices before the elimination of the outliers Source: Śpiewak (2018).

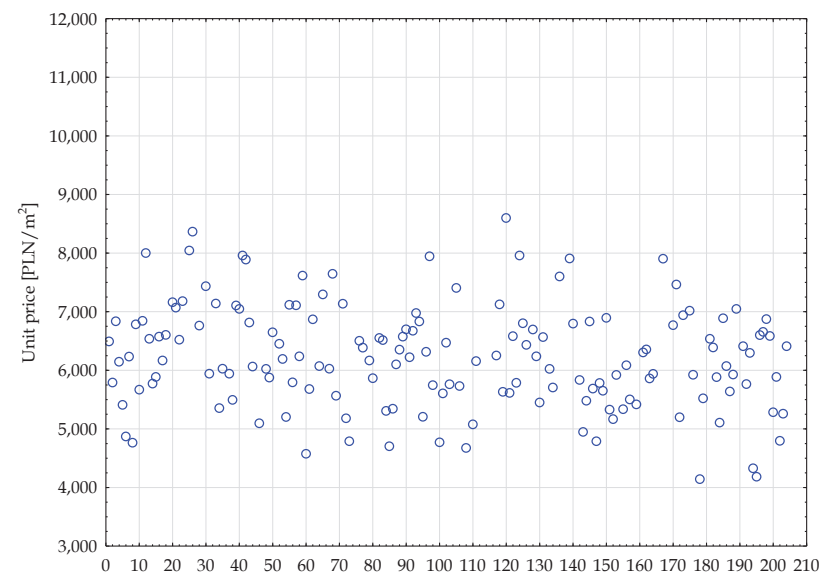

Figure 2. Dispersion graph of the unit prices after the elimination of the outliers by Baarda's method

Source: Śpiewak (2018). 
present the dispersion of the unit prices before the elimination of the outliers (Figure 1) and after their elimination (Figure 2). It can be noticed that the prices of some of the detected properties were significantly different from others, which might confirm the adjustment of the model to the data, not vice versa.

\subsection{Huber's method}

In the first iteration of the estimation of model parameters (1), it was assumed that all the observations had the same weight equaled 1. After the calculation of the multiple linear regression coefficients, the ratio of the observation correction $V$ to the average correction mistake $\sigma_{v_{i}}$ was checked, according to formula (18). In the case when $\bar{v}$ value was higher than parameter $k$, the modification of weight was done for every observation which did not realize

Table 3. Collation of the results of Huber's method for the analyzed market when parameter $k=1.5 \hat{\sigma}_{0}$

\begin{tabular}{|c|c|c|c|c|c|}
\hline No. of iteration & $\begin{array}{c}C_{\text {mean }} \\
\left(\mathrm{PLN} / \mathrm{m}^{2}\right)\end{array}$ & $\begin{array}{c}\hat{\sigma}_{0} \\
\left(\mathrm{PLN} / \mathrm{m}^{2}\right)\end{array}$ & $\begin{array}{l}\text { Variability coefficient } \\
\qquad \frac{\hat{\sigma}_{0}}{C_{\text {mean }}}\end{array}$ & $\begin{array}{c}\text { No. of observations } \\
\text { with changed } \\
\text { weights }\end{array}$ & $\begin{array}{c}\text { Relevant model } \\
\text { variables }\end{array}$ \\
\hline 1 & \multirow{7}{*}{$6,403.52$} & $1,241.61$ & 0.19 & 25 & \multirow{7}{*}{$\begin{array}{c}\text { trans. date, } \\
\text { no. of rooms, } \\
\text { utility floor surf., } \\
\text { access to public } \\
\text { places }\end{array}$} \\
\hline 2 & & $1,134.74$ & 0.18 & 25 & \\
\hline 3 & & $1,135.30$ & 0.18 & 25 & \\
\hline 4 & & $1,135.01$ & 0.18 & 25 & \\
\hline 5 & & $1,135.16$ & 0.18 & 25 & \\
\hline 6 & & $1,135.08$ & 0.18 & 25 & \\
\hline 7 & & $1,135.12$ & 0.18 & 25 & \\
\hline
\end{tabular}

Source: author's own study.

Table 4. Collation of the results of Huber's method for the analyzed market when parameter $k=2$

\begin{tabular}{|c|c|c|c|c|c|}
\hline No. of iteration & $\begin{array}{c}C_{\text {mean }} \\
\left(\mathrm{PLN} / \mathrm{m}^{2}\right)\end{array}$ & $\begin{array}{c}\hat{\sigma}_{0} \\
\left(\mathrm{PLN} / \mathrm{m}^{2}\right)\end{array}$ & $\begin{array}{l}\text { Variability coefficient } \\
\qquad \frac{\hat{\sigma}_{0}}{C_{\text {mean }}}\end{array}$ & $\begin{array}{c}\text { No. of observations } \\
\text { with changed } \\
\text { weights }\end{array}$ & $\begin{array}{c}\text { Relevant model } \\
\text { variables }\end{array}$ \\
\hline 1 & \multirow{7}{*}{$6,403.52$} & $1,241.61$ & 0.19 & 9 & \multirow{7}{*}{$\begin{array}{l}\text { trans. date, } \\
\text { no. of rooms, } \\
\text { utility floor surf., } \\
\text { access to }\end{array}$} \\
\hline 2 & & $1,196.24$ & 0.19 & 10 & \\
\hline 3 & & $1,195.84$ & 0.19 & 10 & \\
\hline 4 & & $1,196.04$ & 0.19 & 10 & \\
\hline 5 & & $1,195.94$ & 0.19 & 10 & \\
\hline 6 & & $1,195.99$ & 0.19 & 10 & \\
\hline 7 & & $1,195.97$ & 0.19 & 10 & \\
\hline
\end{tabular}

Source: author's own study. 
this criterion. All the calculations were made for $k=1.5$ and $k=2$, according to Adamczyk (2017). The results of Huber's method in search for outliers are given in Table 3 and 4.

The value of the variability coefficient $V$ improved marginally for the algorithm where parameter $k=1.5$, in relation to its initial value, which was 0.19 . The next iterations did not cause the decrease of $V$ value, which meant that the process of weight modification for the observations could be completed after the second iteration. The application of Huber's method for parameter $k=2$ did not cause the growth of the multiple linear regression adjustment to the market data, which can be claimed indirectly on the basis of the stable value of estimation mistake $\hat{\sigma}_{0}$.

\section{Conclusions}

As a result of the conducted calculations on using Baarda'a and Huber's methods in the real estate market modeling, outliers were found in the analyzed database. Baarda's method detected 42 observations called outliers, and the removal of them caused the significant growth of the data coherence. Huber's algorithm also detected outliers, and, for these observations, the lower values of weights were introduced. However, Huber's method turned out to be ineffective in the course of further analysis because the value of the variability coefficient did not improve.

Baarda's method is based on statistical tests. The user can influence the number of data called outliers by changing the relevance level. In Huber's algorithm, there is a possibility to change parameter $k$. This parameter determines which observations should have lower values of weights in the next iteration of the estimation of the multiple linear regression parameters.

Taking into consideration the results obtained, passive methods are more rigorous in comparison with the active ones, because outliers are eliminated in their algorithms. The only doubt is about the considerable number of the eliminated observations. Active methods are based on minimizing the influence of the outstanding observations by introducing weights, and, what is important, all the data are contained in the model.

The answer to the question which method is better for the analyzed dataset in the context of preparing them for the real estate market modeling is not easy, and wider research needs to be conducted. Taking into consideration the only value of the variability coefficient, the Baarda's algorithm seemed to be better. However, as many as $21 \%$ of the observations from the initial database were called outliers. It is not certain that these data were not the source of other valuable information, e.g. that something was changing on the analyzed market. Huber's algorithm is based on a full dataset, which means that all the observations take part in modeling. Fewer 
observations were called outliers and their influence was minimized, but not eliminated. It is important that among 42 observations, pointed by Baarda's algorithm, 24 properties were also detected by Huber's method, which confirmed that this group contained observations atypical to others. The question is only about the cause of these outstanding observations, which will be raised in the next publication.

\section{References}

Adamczyk, T. (2017). Application of the Huber and Hampel M-estimation in Real Estate Value Modeling. Geomatics and Environmental Engineering, 1 (11), 15-23. DOI: 10.7494/ geom.2017.11.1.15.

Barańska, A. (2007). Dwuetapowy model wyceny nieruchomości. Journal of the Polish Real Estate Scientific Society, 15 (3-4), 187-195.

Barańska, A. (2010). Statystyczne metody analizy i weryfikacji proponowanych algorytmów wyceny nieruchomości. Rozprawy i Monografie. Kraków: Wydawnictwa AGH.

Barańska, A. (2012). Statystyczna weryfikacja modeli wyceny nieruchomości. Journal of the Polish Real Estate Scientific Society, 20 (1), 29-39.

Baarda, W. (1968). A testing procedure for use in geodetic networks. Netherlands Geodetic Commission, 2 (5).

Bitner, A. (2007). Konstrukcja modelu regresji wielorakiej przy wycenie nieruchomości. Acta Scientiarum Polonorum, Administratio Locorum, 6 (4), 59-66.

Doszyń, M., Gnat, S. (2017). Econometric Identification of the Impact of Real Estate Characteristics Based on Predictive and Studentized Residuals. Journal of the Polish Real Estate Scientific Society, 25 (1), 84-92. DOI: 10.1515/remav-2017-0005.

Huber, P.J. (1964). Robust Estimation of a Location Parameter. The Annals of Mathematical Statistics, 35 (1), 73-101.

Huber, P.J. (1981). Robust statistics. New York: John Wiley \& Sons.

Kamiński, W. (2003). Z odsieczą połowcom. Surveyor, 101, 28-30.

Isakson, H.R. (1998). The Review of Real Estate Appraisals Using Multiple Regression Analysis. Journal of Real Estate Research, 15 (2), 177-190.

Ligas, M. (2010). Metody statystyczne w wycenie nieruchomości. Journal of the Polish Real Estate Scientific Society, 18 (1), 49-64.

Muszyński, Z., Rybak, J. (2008). Zastosowanie metod estymacji odpornej w obliczeniach nośności granicznej pali. Mining and Geoengineering, 32 (2), 257-265. 
Prószyński, W., Kwaśniak, M. (2002). Niezawodność sieci geodezyjnych. Warsaw Polytechnic Publishing House.

Ramsey, J.B. (1969). Tests for Specification Errors in Classical Linear Least-Squares Regression Analysis. Journal of the Royal Statistical Society. Series B (Methodological), 31 (2), 350-371.

Smith, Jr., Everett, V. (2002). Understanding Rasch measurement: Detecting and evaluating the impact of multidimenstionality using item fit statistics and principal component analysis of residuals. Journal of Applied Measurement, 3 (2), 205-231.

Śpiewak, B. (2018). Application of Passive Methods of Robust Estimation: Baarda's and Pope's in Real Estate Market Analysis. Journal of the Polish Real Estate Scientific Society, 1 (1), 5-15.

Walesiak, M. (1996). Metody analizy danych marketingowych. Warszawa: PWN. 